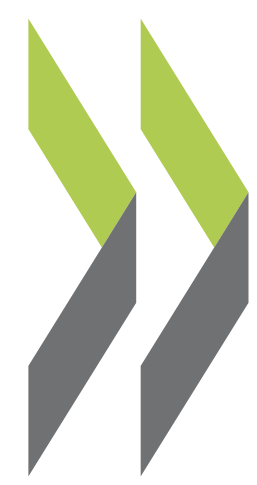

OECD Science, Technology and Industry Working Papers $2002 / 08$

\title{
Linking Innovation to Productivity Growth Using Two Waves of the Community Innovation Survey
}


Organisation de Coopération et de Développement Economiques

DIRECTORATE FOR SCIENCE, TECHNOLOGY AND INDUSTRY

STI Working Paper 2002/8

LINKING INNOVATION TO PRODUCTIVITY GROWTH USING TWO WAVES OF THE COMMUNITY INNOVATION SURVEY

George van Leeuwen 


\section{STI Working Paper Series}

The Working Paper series of the OECD Directorate for Science, Technology and Industry is designed to make available to a wider readership selected studies prepared by staff in the Directorate or by outside consultants working on OECD projects. The papers included in the series cover a broad range of issues, of both a technical and policy-analytical nature, in the areas of work of the DSTI. The Working Papers are generally available only in their original language - English or French - with a summary in the other.

Comment on the papers is invited, and should be sent to the Directorate for Science, Technology and Industry, OECD, 2 rue André Pascal, 75775 Paris Cedex 16, France.

The opinions expressed in these papers are the sole responsibility of the author(s) and do not necessarily reflect those of the OECD or of the governments of its Member countries.

\section{http://www.oecd.org/sti/working-papers}


DSTI/DOC(2002)8

\title{
LINKING INNOVATION TO PRODUCTIVITY GROWTH USING TWO WAVES OF THE COMMUNITY INNOVATION SURVEY
}

\author{
George van Leeuwen ${ }^{*}$ \\ Statistics Netherlands, Methods and Informatics Department, \\ P.O. Box 4000, NL-2270 JM Voorburg, The Netherlands
}

Using two waves of the Community Innovation Survey (CIS) for the Netherlands, this paper integrates recent lines of research to estimate the contribution of innovation to manufacturing multifactor productivity (MFP) growth. The model uses CIS data to control for the complementarity between internal and external knowledge bases, and investigates the importance of within-firm time interdependencies for inputs into innovation and innovation output. The results show the benefits of including more information on the technological environment of firms. Furthermore, the model shows that tracking the innovation performance of the same firms over time leads to a lower persistence of innovativeness when measured from the output side than when measured from the input side through use of R\&D. Moreover, the contribution of innovation to MFP increases when estimating a static innovation model that uses the data obtained after pooling the two waves of CIS. The latter result reflects the difficulty of accounting properly for the non-rivalry of innovation and the associated inter-firm "spillovers" of knowledge creation when using firm-level panel data alone.

* A first version of this paper was presented at the OECD Workshop on Firm-Level Statistics, Paris, 26-27 November 2001. The views expressed in this study are those of the author and do not necessarily reflect the policies of Statistics Netherlands. The author would like to thank Bert Balk for his valuable comments. 
DSTI/DOC(2002)8

\title{
LIENS ENTRE INNOVATION ET CROISSANCE DE LA PRODUCTIVITÉ MIS EN EVIDENCE PAR LES DEUX PREMIERES ENQUÊTES COMMUNAUTAIRES SUR L'INNOVATION
}

\author{
George van Leeuwen ${ }^{*}$ \\ Statistics Netherlands, Methods and Informatics Department, \\ P.O. Box 4000, NL-2270 JM Voorburg, Pays-Bas
}

\begin{abstract}
A partir des deux enquêtes communautaires sur l'innovation (ECI) réalisées pour les Pays-Bas, le présent document reprend les pistes de recherche les plus récentes pour estimer la part de l'innovation dans la croissance de la productivité multi-factorielle. Le modèle s'appuie sur les données des ECI pour vérifier la complémentarité entre les bases de connaissances internes et externes, tout en mesurant l'importance des interdépendances chronologiques à l'intérieur des entreprises, qu'il s'agisse des éléments entrant dans l'innovation ou de la production d'innovation. L'intérêt de prendre en compte davantage d'informations sur le contexte technologique des entreprises est mis en évidence. Le modèle montre en outre qu'en suivant dans le temps les caractéristiques de l'innovation pour les mêmes entreprises, on observe une moindre persistance de la capacité d'innovation si celle-ci est mesurée en termes de résultats que si elle est mesurée en termes de R-D. Qui plus est, la part de l'innovation dans la croissance de la productivité multi-factorielle augmente si on se réfère à un modèle statique de l'innovation qui utilise les données obtenues en regroupant les deux ECI. Ce dernier constat témoigne de la difficulté de rendre compte comme il convient de la non-rivalité entre l'innovation et les «retombées » inter-entreprises de la création de connaissances lorsqu'on se réfère uniquement à des données de panel au niveau de l'entreprise.
\end{abstract}

* Une première version de ce document a été examinée lors de l'Atelier sur les statistiques recueillies au niveau de l'entreprise et leur analyse, qui s'est tenu à Paris les 26 et 27 novembre 2001. Les points de vue exprimés ici sont ceux de l'auteur et ne correspondent pas nécessairement aux orientations de Statistics Netherlands. Je tiens à remercier Bert Balk pour ses commentaires fort utiles. 


\section{Introduction}

About ten years ago, the OECD took the initiative of setting up guidelines for the formulation and design of innovation surveys. Since the emergence of the "Oslo Manual" (OECD, 1992, 1996), a number of countries have launched at least two surveys, known as Community Innovation Surveys (CIS). In contrast to other countries, and prior to the third wave of the large and harmonised European CIS3 survey, which is now underway, Statistics Netherlands carried out an intervening survey (called CIS2 $1 / 2$ ) on the basis of a panel design. This paper presents the results of a first attempt to make use of two similar innovation surveys (CIS2 and CIS2 $1 \frac{1}{2}$ ) and the production surveys for the same reporting units, to construct a panel for both innovation variables and performance measures. ${ }^{1}$ To our knowledge, this is the first example of the use of panel data of innovation variables to investigate a number of theoretical issues raised over the past decade.

Innovation surveys emerged from a growing concern about the deficiencies of traditional $R \& D$ surveys: $i$ ) inputs into innovation were insufficiently covered by $\mathrm{R} \& \mathrm{D}$ expenditures alone; $i i$ ) appropriate and direct measures of the output of the innovation process were lacking; indirect measures such as patent applications were considered insufficient; and iii) data on the organisation of the innovation process and the importance of knowledge flows between firms were required.

It is clear that CIS has opened new routes for the assessment of the contribution of innovation to productivity (growth). First, the use of direct measures of a firm's innovation output enables an explicit estimation of the innovation production function (see e.g. Griliches, 1998). In addition, data on the (firm-specific) characteristics of the innovation process permit a more direct analysis of the importance of knowledge flows between firms or between firms and other organisations, both for building up and maintaining internal knowledge bases or for the output of the innovation process. Second, if direct measures of innovation output are available, some of the disadvantages of the widely used knowledgecapital-stock approach can be circumvented. Third, embedding the innovation production function in a structural model enables a better understanding of the complex links between innovation and productivity growth. By allowing greater structure (more equations) and by providing new instruments, the new data sources are a step forward in the search for the identification of the contribution of innovation, or more specifically R\&D, to productivity growth along the lines proposed in Griliches and Mairesse (1997).

Since the harmonised CIS data have become available, relatively few studies have tried to use the new data for the purpose of estimating the contribution of innovation to firm performance. Recent examples are presented in Crépon et al. (1998), Lööf and Heshmati (2001) and Klomp and van Leeuwen (2001). All these studies could use only one wave of CIS. In the present paper, previous cross-sectional analysis by is extended using the two waves of CIS to incorporate recent lines of research in a structural modelling approach. Adaptations of the model for knowledge-stock accumulation suggested by, among others, Hall and Hayashi (1989) and Klette (1996) and the revenue approach of Klette and Griliches (1996), are used to embed the innovation process in a model that aims to explain differences in productivity growth. The model simultaneously takes into account the importance of innovation for the competitive environment of firms and uses the innovation panel to investigate the within-firm time interdependencies of innovation output and the importance of inter-firm knowledge flows.

1. In the Netherlands, CIS1 (covering 1992-94) and CIS2 (covering 1994-96) were conducted by different institutions. As a consequence of the use of different sampling frames, it appeared to be impossible to link these surveys at the micro level and to use the linked data for analysing the dynamics of innovation. Another difference between the two surveys concerns the questions asked and the reporting unit. From CIS2 onwards, the CIS surveys are considered to be harmonised and are conducted in more or less the same fashion. 
The model adaptations yield a dynamic system for the innovation process which, on the one hand, may present a better description of the intricacies of the process but, on the other hand, introduce a myriad of other problems. The first results show that many firms that innovated in CIS 2 were absent in CIS2 $1 / 2$. Nevertheless, the coverage of innovating firms was very similar in the two surveys. This loss of data severely complicates the use of a dynamic innovation model as it may be due to discontinuities of the innovation process itself (e.g. triggered by the depletion of technological opportunities). In the estimation procedure, I have tried as far as possible to control for this source of endogenous attrition. Furthermore, the results obtained using the dynamic innovation equations in the full model are compared with those from implementing a static version of the innovation model that can be applied to a more extensive data set.

The plan of the paper is as follows. Sections 2 and 3 discuss the derivation of the dynamic innovation model and the linking of this model to the proposed model for productivity growth. Section 4 discusses the construction of the data. In this section, some descriptive measures that enable a comparison of the performance of innovating and non-innovating firms are presented. The estimation results for the various models are presented in Section 5. Section 6 summarises and concludes.

\section{The link with previous research}

\subsection{Adaptations of the basic framework}

In this section, some adaptations of the basic framework proposed in the recent literature are outlined (see Appendix 1 for a summary of this framework). These adaptations concern: $i$ ) modification of the model for the process of knowledge accumulation underlying the R\&D production function framework; and ii) extension of the traditional reduced-form R\&D models in the direction of a structural model as an attempt to exploit the CIS data. The first strand of research (which is the subject of subsection 2.1) discusses the separability of current R\&D efforts and the internal knowledge base previously acquired. The second strand of research (discussed in subsection 2.2) models innovation as a separate process and discusses how this process can be linked to overall firm performance. A link is established between the two strands of research by combining a (reduced-form) revenue model and a dynamic model for the innovation process.

\subsection{The process of knowledge accumulation}

Many discussions concerning the traditional R\&D-productivity framework are centred around the concept of knowledge production and how the usually applied procedure of constructing R\&D-capital stocks fits into this concept. The disadvantages of using the capital-accumulation equation for firm $i(i=1$, $\ldots, N)$ in year $t(t=1996,1998)$ :

$$
K_{i t}=(1-\delta) K_{i t-1}+R_{i t}
$$

as a model for knowledge production have been discussed extensively in the literature (see e.g. Griliches, 1998). In this framework, $K$ is a measure of knowledge stocks and $R$ a measure of $R \& D$ or innovation investment. In this paper, the focus is on the central point of criticism which concerns the separability of current R\&D efforts and the level of innovativeness already achieved.

As the equation is homogeneous of degree one in current $R \& D$, Equation (1) implies constant returns of $R \& D$ to knowledge production. Thus (1) neglects any complementarity between current R\&D and the knowledge already captured in the existing stock or the history of R\&D investment. Griliches (1998) has pointed out that the process of knowledge production of firms induced by their own R\&D history may be 
different in this respect from other capital investment. A firm's R\&D investment may depend in a non-linear fashion not only on its current own $\mathrm{R} \& \mathrm{D}$, but also on (own) previously accumulated results derived from R\&D and - moreover - on the absorption of knowledge from its technological environment.

An alternative specification provided by e.g. Hall and Hayashi (1989) and Klette (1996) gets to the core of this criticism and is given by:

$$
K_{i t}=K_{i t-1}^{\rho-v} R_{i t-1}^{v}
$$

From Equation (2a), it can be shown that the marginal product of $R \& D$ is inversely related to the current R\&D effort, which implies decreasing returns of R\&D to knowledge capital. ${ }^{2}$ Klette (1996) rationalises (2a) as follows: “... the complementarity in knowledge production may explain why firms with a high rate of return to knowledge capital may have little incentive to carry out R\&D because they may have too little knowledge capital or too few $R \& D$ skills to get much knowledge out of new $R \& D$ investment. Similarly, firms with a low rate of return to knowledge capital might prefer to carry out more $\mathrm{R} \& \mathrm{D}$ as the knowledge capital already acquired makes the current R\&D effort more productive ...".

Taking logarithms of the variables and adding a constant term, expression (2a) can be transformed into:

$$
k_{i t}=\mu_{3}+\theta_{1} k_{i t-1}+\theta_{2} r_{i t-1}
$$

The parameters of interest in (2b) are $\theta_{1}$ and $\theta_{2}$. If $\theta_{1}$ is larger (smaller) than one, then there are increasing (decreasing) returns in the knowledge-production function. The estimate of $\theta_{2}$ represents the innovation opportunities of $\mathrm{R} \& \mathrm{D}$. The estimate of $\theta_{1}$ can be considered as a measure of the persistence of the knowledge capital already acquired. A high value signals significant scale economies in R\&D. An estimate larger than one points to a cumulative process, whereby an above-average firm departs more and more from the average firm, even if its R\&D efforts are average. ${ }^{3}$ By contrast, a low value of $\theta_{1}$ signals a low persistence of knowledge capital. This may be due to the depletion of technological opportunities as a result of (unintended) spillovers and diffusion of knowledge to competitors. In this case, there is a tendency to convergence, as a firm with above-average knowledge capital gravitates down towards the average firm, even if it carries out an average amount of $R \& D$.

The usual procedure to implement (2b) in the empirical model is to find some way to solve the unobservable $k$. Klette (1996) achieved this by combining a demand model with an equation for productivity differences relative to a reference firm (represented by the average over all firms). The empirical model finally obtained is a dynamic equation in Solow-residual productivity differences with the contribution of innovation represented by (the logarithm of) lagged R\&D. Thus, in essence, this remains a (modified) reduced-form R\&D model. Besides the drawback that these types of models remain based on

2. Equation (2a) has the undesirable property that knowledge capital vanishes if R\&D expenditure is zero. This problem can be taken into account in the estimation procedure by imputing one (guilder) for R\&D and using a "no-R\&D" dummy variable in the regression model.

3. This interpretation can be obtained after using deviations from the means of the variables included in (2b). 
measures of inputs into innovation, ${ }^{4}$ they also suffer from the disadvantage that the importance of knowledge flows between firms is not taken into account.

\subsection{Structural modelling approaches}

It is at this stage that the CIS data come into play. The main feature of CIS is that the survey is directed at the innovation process itself. The CIS surveys aim to describe the innovation process by collecting data on the inputs into innovation (investment in innovation disaggregated by type), innovation output (measured by the share of new or improved sales in total sales), and data to describe the technological environment of firms and the importance of inter-firm knowledge flows.

One of the new variables collected, which seems to be most promising in view of the problems encountered in previous research, concerns the direct measurement of innovation output, represented by the share of new and improved sales in total sales. It seems straightforward to use this variable and the data on the firm-specific characteristics of the innovation process for the estimation of a (enhanced) knowledge production function as an alternative for $(2 b)$.

Unfortunately, this new approach has a price. A first problem to note is that innovation output should be linked to overall firm performance in some way, in order to enable an assessment of the contribution of innovation to productivity (growth). The change from input to output measures would aggravate the endogeneity problem ${ }^{5}$ since the productivity equations would contain an output measure as one of the explanatory variables. A second point concerns the definition of innovation output: Which choice between the available alternatives should be made? For instance, should one use (the share of) new products or new and improved products, products new to the firm, or products new to the market? Third, is innovation output measured in this way equivalent to the output of a knowledge-production function or, more precisely, the result of applying the knowledge-capital accumulation equation given by $(2 \mathrm{~b})$ ?

\section{Adaptations of our previous model}

\subsection{The derivation of an enhanced productivity-growth equation}

Recent studies (see e.g. Crépon et al., 1998; van Leeuwen and Klomp, 2001) have exploited the new CIS data in a structural modelling approach. These approaches claim that it is not differences in innovation investment (or, more specifically, the history of R\&D investment), but rather differences in innovation output that determine the observable differences in productivity (growth). In this section, an extension of the model used in van Leeuwen and Klomp (2001) is presented. The proposed model aims to capture the theoretical issues of the preceding section and makes more extensive use of the CIS data than does the study by Crépon et al. (1998). Similar to Klette (1996), a firm's total sales are used as the starting point for the model derivation but, contrary to his study, sales performance of firms is embedded in a market-share model. Therefore, the model proposed here is similar to that of Klette and Griliches (1996), with the difference an innovation output measure is used to capture the impact of "demand shifts" on sales-peremployee growth. This adaptation can be argued as follows. Saying that innovation output is similar to

4. A central problem related to the use of input measures remains the unknown relationship between $R \& D$ investment and the output of the innovation process. This concerns, among others, the time delay between R\&D investment and innovation success, or the depletion of technological opportunities built up by the history of R\&D investment.

5. This econometric problem also complicates the use of traditional R\&D models as one may expect that the $\mathrm{R} \& \mathrm{D}$ investment decision may be dependent on firm performance. 
relative product quality, by definition implies that innovating firms are operating in markets characterised by horizontal product differentiation. Thus, one might expect that successful innovators have discretion in market power; this makes their relative prices endogenous. by:

Let the differential equation for the market share of firm $i$ operating in market (industry) $I$ be given

$$
\Delta q_{i}^{d}-\Delta \bar{q}_{I}=\Delta d_{i}+\eta \Delta\left(p_{i}-\bar{p}_{I}\right)^{6}
$$

In (3a) $q_{i}^{d}, p_{i}$ and $\bar{q}_{I}$ denote respectively the demand and own price (index) of firm $i$ and total sales of market (industry) $I$. Furthermore, $\eta$ represents the demand elasticity with respect to relative prices (or, stated otherwise, the "own" price index relative to the aggregate deflator for industry $I$ ) and $\Delta d_{i}$ summarises the contribution of "demand-shifting" variables to the growth rate of a firm's own demand relative to the growth of exogenously given sales opportunities, represented by $\Delta \bar{q}_{I}$.

The proposed model adopts a parametrisation of the "demand shifter" that uses the data on crosssectional differences in relative product quality observed in CIS. More precisely, $\Delta d_{i}=\phi S_{i}$ is used, with $S_{i}$ the share of new (or new and improved) sales in total sales. Taking into account the definition of the growth rate of deflated revenues $\left(\Delta r_{i}\right)$, expressed as:

$$
\Delta r_{i}=\Delta\left(q_{i}+p_{i}\right)-\Delta \bar{p}_{I}
$$

and after equating demand and output, and combining (3a) and (3b) with a traditional gross output production-function model, ${ }^{7}$ this yields:

$$
\Delta r_{i t}=\varepsilon\left(\alpha \Delta c_{i t}+\lambda \Delta m_{i t}+\beta \Delta l_{i t}\right)-\frac{1}{\eta} \Delta \bar{q}_{I t}-\frac{\phi}{\eta} S_{i t}+e_{1 i t}
$$

where $\varepsilon$ represents the inverse of the mark-up factor, ${ }^{8} e_{1 i}$ is a disturbance term and a time subscript is added to distinguish between observation periods.

In the empirical application, the productivity equivalent of (3c) is used after adding a constant term and dummy variables to capture a general trend and the impact of process innovation on a firm's revenueper-employee growth respectively. ${ }^{9}$ Therefore, the empirical specification for the revenue-per-employee equation of our model reads:

6. Equation (3a) is the "long-difference" form of the market-share equation, where the "long-difference" operator $\Delta$ refers to annualised growth rates calculated for the periods 1994-96 and 1996-98.

7. The model uses as inputs into production ordinary physical capital (C), labour (L) and material inputs (M) (see Appendix 1).

8. The inverse of the mark-up factor is related to the price elasticity of demand as follows: $\varepsilon=(\eta+1) / \eta$.

9. This dummy variable takes on a value of one if a firm stated having implemented process innovation, and zero otherwise. 


$$
\begin{gathered}
\Delta r_{i t}-\Delta l_{i t}=\mu+\varepsilon \alpha\left(\Delta c_{i t}-\Delta l_{i t}\right)+\varepsilon \lambda\left(\Delta m_{i t}-\Delta l_{i t}\right)+\varepsilon(\alpha+\beta+\lambda-1) \Delta l_{i t} \\
-\frac{1}{\eta} \Delta \bar{q}_{I t}+\gamma S_{i t}+\xi D_{p r o c, i t}+e_{2 i t}, \text { where } \gamma=-\frac{\phi}{\eta}
\end{gathered}
$$

The estimation of (4) yields an explicit estimate of the contribution of innovation to multifactor productivity growth (MFP), given by $\hat{\gamma} \bar{S}=-(\hat{\phi} / \hat{\eta}) \bar{S}$, and also controls for biases in the returns-to-scale estimates. ${ }^{10}$ Note that, contrary to the basic framework (see Appendix 1), innovation investment is no longer interpreted as a separate input. Instead, the model assumes that differences in innovation intensities are transmitted to differences in revenue-per-employee growth to the extent that a firm's investment endeavour has been successful.

\subsection{Linking the revenue model to the innovation process}

The next step is to embed (4) in a structural model that is sufficiently flexible to capture important features of the innovation process and that takes into account the joint endogeneity of innovative sales and sales-per-employee growth. By "sufficiently flexible", I mean that the model should be able to account for within-firm time interdependencies of knowledge production, as well as the various interactions between internal and external knowledge bases. However, this is a daunting task in view of the available data and the intricacies involved. Many variables collected in CIS are of a qualitative nature and the issue of how to use these data optimally together with the continuous variables for innovation investment and innovation output remains an open question. A related problem is that a firm's technological environment may affect its innovation investment and its level of innovation output achieved at the same time.

A recurrent conclusion of previous research (see e.g. Cohen and Levinthal, 1989; Leiponen, 2001; Veugelers, 1997; Veugelers and Cassiman, 1999), is that the technological environment of a firm may affect its organisational arrangements. Firms absorb knowledge from the environment via supplierproducer-customer interactions, the use of available information sources in addition to building up and maintaining their own knowledge bases via R\&D investment and (R\&D) co-operation. The choice between the "make", "buy" or "make-and-buy" option, on the one hand, and between "formal" and "informal" R\&D or - more general - innovation, on the other, may have diverging impacts on the level and composition of innovation costs. Moreover, utilising the technological environment may also contribute to innovation output more directly. For instance, one can imagine that firms innovate by exploiting the available information sources or by relying on informal innovation co-operation, without spending a single dollar on R\&D.

In order to account for the complementarity between internal and external knowledge bases and knowledge flows between firms, $R \& D$ investment decision and the level of innovative sales achieved are assumed to be jointly dependent on various firm-specific innovation characteristics. ${ }^{11}$ In addition, the within-firm time interdependencies is modelled for the two stages of the innovation process by adopting a

10. $\bar{S}$ represents the average share of innovative sales and the estimate for $\alpha+\beta+\lambda-1$ in (4) represents the deviation from constant-returns-to-scale.

11. A description of all instrumental variables is given in Appendix 2. 
dynamic specification for the R\&D intensities (denoted by R/Q) as well as for the (logarithm of the) share of new sales in total sales. ${ }^{12}$ This yields the following two equations:

$$
\begin{aligned}
& (R / Q)_{t}=\pi_{10}+\pi_{11}(R / Q)_{i t-1}+\pi_{12} \ln \left(S_{i t-1}\right)+X_{1 t}^{\prime} \Pi_{13}+Z_{1 t}^{\prime} \Pi_{14}+e_{r t} \\
& \ln \left(S_{i t}\right)=\pi_{20}+\pi_{21} \ln \left(S_{i t-1}\right)+\pi_{22}(R / Q)_{i t}+X_{2 t}^{\prime} \Pi_{23}+Z_{2 t}^{\prime} \Pi_{24}+e_{s i t},
\end{aligned}
$$

The capital $\Pi \mathrm{s}$ in $(5 \mathrm{a})$ and $(5 \mathrm{~b})$ denote vectors of parameters associated with the instrumental variables (other than the lagged dependent variables included). These variables are collected in two vectors: $\mathrm{X}$ (for production survey data) and $\mathrm{Z}$ (for innovation survey data). The identification of the model rests on the partitioning of these vectors across the two equations. A similar partitioning to that used in van Leeuwen and Klomp (2001) has been chosen:

$$
\begin{gathered}
X=\left\{M S_{t-1}, \Delta \bar{q}_{I}, l_{t-1}, C F_{t-1}\right\} \\
Z=\left\{D_{\text {pull } 1}, D_{\text {pull } 2}, D_{\text {push } 1}, D_{\text {push } 2}, \text { SCIENCE }, \text { OTHER }, D_{c o-o p}, D_{R \& D}\right\} \\
Z_{1}=\left\{Z, D_{\text {subs }}\right\}, X_{1}=\left\{M S_{t-1}, \Delta \bar{q}_{I}, l_{t-1}, C F_{t-1}\right\} \\
Z_{2}=\left\{Z, D_{\text {proc }}, P A V I T\right\} \text { and } X_{2}=\left\{\Delta \bar{q}_{I}, l_{t-1}\right\} .{ }^{13}
\end{gathered}
$$

Note that (5a) generalises (2b) and that the system (5) as a whole can be used to compare the differences between the persistence of R\&D input and innovation output. In addition, an estimate for the impact of the initial level of innovativeness (represented by $\ln \left(S_{t-1}\right)$ ) on the current R\&D endeavour is obtained. Furthermore, system (5) can be reduced to a static version by removing the lagged endogenous variables, thus enabling comparison with our previous research.

\section{The data}

\subsection{The linking of innovation and production survey data}

The data used in this paper are obtained by matching the two waves of CIS to the production surveys for manufacturing. In general, the two innovation surveys asked the same questions and were based on the same sampling frame that underlies the production surveys. Thus, in principle, matching the two innovation surveys is straightforward. However, an exception should be made for a few enterprises that have their R\&D function centralised in special units. As their innovation data for 1996-98 were collected in a different way than the corresponding data for 1994-96 (CIS2), these data have not been used.

The model makes extensive use of market (industry) variables. Therefore, industry data on nominal sales were first constructed for the years 1994, 1996 and 1998. Using the raising factors of the underlying production surveys, the value of total sales was calculated at the ISIC three-digit level for each year.

12. I use the R\&D intensity form and the logarithmic transformation of $S$ in (5a) and (5b) because this enables a comparison with, for example, Crépon et al. (1998) and van Leeuwen and Klomp (2001). Furthermore, to be consistent with (5a) and (5b), I replaced $S$ in (4) by $\exp \{\ln (S)\}$.

13. PAVIT denotes a set of dummy variables which represent the industry classification of firms according to technology regimes. See Appendix 2 for an explanation of the other instruments collected in $X$ and $Z$. 
Subsequently, these data were linked to the corresponding industry price indices for total sales and material usage. ${ }^{14}$ In the next step, a set of complete firm-level production survey data was constructed for the two periods covered by the innovation surveys. In order to obtain two short panels, firms with complete production survey data in 1994 and 1996 or 1996 and 1998 were selected. The cleansing rules eliminated firms with a negative score for their value added or missing data on employment, the cost of material usage and depreciation costs. In addition, and to safeguard against a mismatch with the industry data, firms that showed a change in their (three-digit) ISIC classification were also eliminated. ${ }^{15}$

To estimate the parameters of the productivity growth equation of the model, data on labour input, material usage and physical capital are also needed. The first two variables are readily available, although for labour input "head counts" (number of employees) are the only variable available. Unfortunately, not uncommonly for this type of data, measures of capital input raise more problems. The capital input measure used to estimate the models is approximated by the depreciation costs (deflated with the price index for total sales) available in the production surveys. ${ }^{16}$ Similarly, the other nominal variables in the data set were deflated after linking the industry data to the firm-level data, by applying the industry sales or material price indices to all firms within the corresponding industry. In the final stage of the data construction, the two innovation surveys were linked to the corresponding production survey panels after removing firms with a suspiciously high innovation intensity. ${ }^{17}$

A summary of the resulting data is given in Table 1. It should be noted that the second period covers many more very small firms than the first period. This applies to the production survey as well as to the innovation survey. Nevertheless, the CIS coverage ratios for the two periods are more or less the same (about $60 \%$ ). For the coverage with respect to innovating firms, the result is similar: the share of innovating firms as a percentage of all firms covered by CIS differs only slightly between the periods covered by CIS 2 and CIS $2 \frac{1}{2}$. However, if a balanced innovation panel is used, then the coverage ratio of CIS decreases to $36 \%$ (last column of Table 1). This unexpected result may have different causes and deserves further investigation. On the other hand, it can be seen that the use of a balanced innovation panel may invoke another selectivity problem, as the percentage share of innovating firms is larger for the balanced innovation panel (65\%, compared to 57\% in 1994-96 and 54\% in 1996-98). The latter result may be due to the combined effect of a higher probability of survival and a higher persistence of innovativeness for larger firms.

In closing, it should be noted that the definition of "innovativeness" used in this study differs from that used in Statistics Netherlands (2000). In the present study, firms that responded to CIS are labelled "innovative" if they have a complete set of data on innovation investment, innovation output and the qualitative variables referring to the technological environment. By contrast, Statistics Netherlands (2000) uses a broader definition, and firms are classified as "innovative" if they have carried out innovative activities in some way. In the latter definition, firms are considered to be "innovative" even if they did not

14. The price indices represent the average change in prices compared to 1990 (the base year). Their level of detail varies between the two- and three-digit level of the ISIC industry classification of firms, with a greater level of detail for the sales deflators than for the price indices for materials use.

15. A firm for which the three-digit industry classification changed in 1994-96 was eliminated from the panel for this period. Nevertheless, this firm can be included in the panel for 1996-98, provided that its classification did not change in the latter period.

16. This financial measure is related to the capital stock but does not reflect directly the capital service flow. Tax laws, vintage structures and type distribution of the assets, and cyclical capital utilisation all cause differences between the depreciation data and the desired measure of real capital input.

17. Firms covered in CIS 2 or CIS $2 \frac{1}{2} 2$ were removed from the data if their innovation intensity (total innovation cost scaled by nominal sales) exceeded $50 \%$. 
actually implement any product or process innovation in the period considered. For these firms, the variables included in the model discussed above are not available.

Table 1. Summary of the data sets available for manufacturing

\begin{tabular}{lccc}
\hline & $1994-96$ & $1996-98$ & $1994-98$ \\
\hline Complete production survey data & 4134 & 5087 & 3180 \\
Covered in CIS & 2516 & 3012 & 1160 \\
$\quad$ Innovative & 1428 & 1618 & 758 \\
$\quad$ Non-innovative & 1088 & 1394 & 402 \\
\hline
\end{tabular}

\subsection{A comparison of the performance of innovating and non-innovating firms}

Tables $2 \mathrm{a}$ and $2 \mathrm{~b}$ present some simple descriptive measures for the key variables used in this study, enabling a comparison of the performance of innovative (I) and non-innovative (N) firms for 1994-96 and 1996-98. On the whole, the tables confirm our previous result (Klomp and van Leeuwen, 2001) that innovative firms perform better than non-innovative firms. This conclusion applies to all the performance measures, except for the industry variables. The latter result shows that general business conditions did not favour innovative firms in particular. The most striking difference between the two periods concerns the growth rate of employment. The accelerating growth of industry sales in 1996-98 shows up as positive employment growth in this period, in particular for innovative firms. However, I do not observe a similar acceleration of sales-per-employee growth. Moreover, the acceleration of labour productivity growth (measured as value-added-per-employee) appears to be modest.

Table 2a. Descriptive statistics for selected variables in $1994-96^{1}$

\begin{tabular}{|c|c|c|c|c|}
\hline Variable & Median & Q1 & Q3 & SD \\
\hline \multicolumn{5}{|l|}{ Growth rate of: ${ }^{2}$} \\
\hline Employment (I) & 0.0 & -3.8 & 4.6 & 11.0 \\
\hline Employment (N) & 0.0 & -4.6 & 4.6 & 13.5 \\
\hline Value added per employee (I) & 2.0 & -4.5 & 8.6 & 15.8 \\
\hline Value added per employee $(\mathrm{N})$ & 1.4 & -5.6 & 8.9 & 19.2 \\
\hline Sales per employee (I) & 3.3 & -2.6 & 9.6 & 13.8 \\
\hline Sales per employee $(\mathrm{N})$ & 2.6 & -3.9 & 9.7 & 16.2 \\
\hline Industry sales (I) & 3.6 & 1.2 & 6.9 & 7.7 \\
\hline Industry sales (N) & 3.5 & 1.4 & 5.8 & 6.7 \\
\hline \multicolumn{5}{|l|}{ Levels: } \\
\hline Market share 1994 (\%) (I) & 0.6 & 0.2 & 1.9 & 7.6 \\
\hline Market share $1994(\%)(\mathrm{N})$ & 0.2 & 0.1 & 0.6 & 4.1 \\
\hline Employment 1994 (I) & 89 & 53 & 175 & 1152.8 \\
\hline Employment $1994(\mathrm{~N})$ & 42 & 28 & 73 & 224.9 \\
\hline Profitability 1996 (\%) (I) & 9.8 & 5.1 & 16.5 & 13.9 \\
\hline Profitability $1996(\%)(N)$ & 8.4 & 3.3 & 14.9 & 14.4 \\
\hline Value added per employee $1996(I)^{3}$ & 97.0 & 76.5 & 131.7 & 82.2 \\
\hline Value added per employee $1996(\mathrm{~N})^{3}$ & 84.4 & 66.3 & 109.6 & 82.3 \\
\hline Sales per employee $1996(I)^{3}$ & 251.1 & 184.3 & 373.8 & 422.0 \\
\hline Sales per employee $1996(N)^{3}$ & 212.6 & 151.7 & 317.5 & 565.4 \\
\hline
\end{tabular}

1. Number of innovative firms $(\mathrm{I})=1428$; number of non- innovative firms $(\mathrm{N})=1088$.

2. Annualised growth calculated over the period 1994-96.

3. In NLG thousand. 


\section{DSTI/DOC(2002)8}

The simple descriptive measures used for the level data point to some well-known stylised facts as the tables show that size distributions are very skewed and that innovative firms are smaller and have higher median values for the market shares. It can also be seen that the different sampling design for the period 1996-98 shows up in a lower median value for employment, both for innovative and non-innovative firms.

Table 2b. Descriptive statistics for selected variables in $1996-98^{1}$

\begin{tabular}{|c|c|c|c|c|}
\hline Variable & Median & Q1 & Q3 & SD \\
\hline \multicolumn{5}{|l|}{ Growth rate of: ${ }^{2}$} \\
\hline Employment (I) & 1.3 & -2.5 & 7.0 & 14.0 \\
\hline Employment $(\mathrm{N})$ & 0.4 & -3.2 & 7.7 & 17.6 \\
\hline Value added per employee (I) & 2.3 & -4.8 & 9.8 & 17.8 \\
\hline Value added per employee $(\mathrm{N})$ & 1.7 & -6.7 & 10.3 & 21.9 \\
\hline Sales per employee (I) & 3.2 & -3.3 & 9.7 & 17.4 \\
\hline Sales per employee $(\mathrm{N})$ & 2.2 & -5.5 & 10.1 & 21.6 \\
\hline Industry sales (I) & 5.4 & 2.3 & 6.9 & 5.3 \\
\hline Industry sales $(\mathrm{N})$ & 5.4 & 1.4 & 6.9 & 5.9 \\
\hline \multicolumn{5}{|l|}{ Levels: } \\
\hline Market share $1996(\%)(\mathrm{l})$ & 0.4 & 0.1 & 1.6 & 6.8 \\
\hline Market share $1996(\%)(\mathrm{N})$ & 0.2 & 0.1 & 0.5 & 4.1 \\
\hline Employment 1996 (I) & 74 & 34 & 159 & 1077.5 \\
\hline Employment $1996(\mathrm{~N})$ & 30 & 15 & 57 & 170.7 \\
\hline Profitability 1998 (\%) (I) & 10.1 & 4.8 & 16.4 & 13.7 \\
\hline Profitability $1998(\%)(\mathrm{N})$ & 9.9 & 4.3 & 18.0 & 16.6 \\
\hline Value added per employee $1998(\mathrm{I})^{3}$ & 99.0 & 77.7 & 133.4 & 138.9 \\
\hline Value added per employee $1998(\mathrm{~N})^{3}$ & 88.4 & 67.4 & 118.8 & 72.3 \\
\hline Sales per employee $1998(I)^{3}$ & 264.7 & 187.5 & 394.6 & 834.6 \\
\hline Sales per employee $1998(N)^{3}$ & 218.1 & 150.5 & 337.9 & 1751.3 \\
\hline
\end{tabular}

1. Number of innovative firms $(\mathrm{I})=1618$; number of non-innovative firms $(\mathrm{N})=1394$.

2. Annualised growth calculated over the period $1996-1998$.

3. In NLG thousand.

\section{Estimation results}

\subsection{Selectivity issues}

In this section, the estimation results for the various implementations of the full model are presented. In all implementations the estimated system contains the productivity-growth Equation (4), but I shall iterate on the functional form of the equations that refer to the innovation process. In any case, the estimation of the system takes into account the simultaneity of innovation investment, innovation output and productivity growth. The data allow a breakdown for the total for innovation cost and I can also choose between different measures of innovative sales. In order to keep things tractable, and to preserve the link with previous $R \& D$-productivity research, $R \& D$ intensity was chosen as the measure of inputs into innovation. For the output side of the innovation process, I have chosen to compare the model estimates obtained after using two alternative measures: the share of new sales (new to the firm) in total sales; and the share of new and improved sales in total sales. I begin by using the second measure ${ }^{18}$ and then recalculate our models using the first definition of innovation output.

18. This measure has also been used in our previous research (van Leeuwen and Klomp, 2001). 
In the estimation procedure, I try to correct for possible biases due to selectivity problems. A priori reasoning suggests that the emergence of such problems may be dependent on the adopted specification for the innovation model. For instance, if (5a) and (5b) are used as the model for the innovation process, then the complete system can only be estimated using the firms that were innovative in the two periods considered. In this case, a severe loss of information is encountered. This problem can be overcome by transforming (5a) and (5b) into a static version by removing the lagged dependent variables from the equations.

However, this change of modelling strategy is not trivial in view of the very nature of the process of "knowledge production" and the measure used for the output of this "production process". It may be the case that part of the sample attrition is due to discontinuities in knowledge creation (or more precisely the generation of new or improved products) at the firm level. Put simply: "the fact of having achieved new or improved sales in 1994-96 may reduce the incentive to innovate in 1996-98, as the technological opportunities may be depleted". All this is tantamount to saying that a problem of endogenous attrition may be encountered if a dynamic innovation model is used. Note that the selectivity issue can be carried over to the use of a static version of (5a) and (5b): a situation might arise in which firms facing favourable sales opportunities have less incentive to engage in innovation.

The usual way to account for this type of problem is to apply generalised Tobit models to the equations of the dynamic or static innovation model. These models have been applied as a first step in the estimation procedure. By doing so, the joint dependence on the available exogeneous variables can be assessed for the probability of being innovative as well as for the dependent variables of the two innovation equations. To save space, the results will not be discussed in great detail in the present paper (see Appendix 3 for the model estimates). The main conclusion is that the selectivity problem is more severe for innovation inputs than for innovation output.

The next step consists of finding a way to control for possible selectivity biases of the estimates of the full model. This has been achieved as follows. Dependent on the results of the Tobit analysis, selectivitycorrection terms derived from Heckman's two-step method were added. Furthermore, and only for the full model that uses the static innovation equations, time dummy variables were added to all equations of the full model to control for period-specific effects. It should be borne in mind that the dynamic version of the full model is estimated for the period 1996-98, and uses the data for the 758 firms that were innovative in 1994-96 as well as in 1996-98 (Table 1). ${ }^{19}$ The full model, with the static version of the innovation equation included, uses the 3046 firms that were innovative in either 1994-96 or in 1996-98.

The two versions of the full model are estimated with the help of the method of Full Information Maximum Likelihood (FIML). The FIML estimates are presented in Tables 3 and 4. First, I look at the estimates for the equations of the innovation process, thereby focusing on two central themes: $i$ ) the persistence of innovativeness; and $i$ ) the returns to R\&D investment.

19. The data for 1994-96 were used to construct the lagged dependent variable in the innovation equations. 
Table 3. Results of the innovation-input and innovation-output equation

\begin{tabular}{|c|c|c|c|c|}
\hline \multirow[t]{2}{*}{ Type of model } & \multicolumn{2}{|c|}{ Dynamic model $^{1}$} & \multicolumn{2}{|c|}{ Pooled model $^{1}$} \\
\hline & Est. & $\mathrm{t}$ & Est. & $\mathrm{t}$ \\
\hline Number of firms & 758 & & 3046 & \\
\hline \multicolumn{5}{|l|}{ A) R\&D intensity 1996 or 1998} \\
\hline Constant & 2.792 & 2.0 & 6.269 & 7.2 \\
\hline R\&D intensity 1996 & 0.434 & 24.2 & & \\
\hline Innovation output 1996 & -0.014 & -0.2 & & \\
\hline Size 1994 or 1996 & -0.255 & -2.0 & -0.784 & -7.4 \\
\hline Market share 1994 or 1996 & 0.042 & 5.8 & 0.034 & 8.2 \\
\hline Subsidy awarded & 0.269 & 1.1 & 0.582 & 3.9 \\
\hline Cash-flow ratio 1994 or 1996 & -0.004 & -0.6 & -0.005 & -1.7 \\
\hline Permanent R\&D facilities & 0.505 & 1.6 & 0.895 & 4.7 \\
\hline Innovation co-operation & 0.156 & 0.8 & 0.258 & 2.1 \\
\hline Technological opportunity "Science" & 0.247 & 2.9 & 0.544 & 13.5 \\
\hline Technological opportunity "Other" & 0.062 & 0.5 & 0.150 & 2.3 \\
\hline Demand-pull important & -0.108 & -0.2 & -0.155 & -1.0 \\
\hline Demand-pull very important & 0.029 & 0.1 & 0.023 & 0.1 \\
\hline Technology-push important & 0.182 & 1.0 & -0.181 & -1.6 \\
\hline Technology-push very important & -0.016 & -0.1 & -0.220 & -2.0 \\
\hline Industry sales growth $1994-96$ or $1996-98$ & 0.001 & 0.7 & 0.042 & 6.2 \\
\hline Period dummy & & & -0.294 & -2.4 \\
\hline Heckman's selectivity correction & -2.912 & -1.9 & -2.250 & -6.3 \\
\hline Pseudo $\mathrm{R}^{2}$ & 0.522 & & 0.169 & \\
\hline \multicolumn{5}{|l|}{ B) Innovation output 1996 or $1998^{2}$} \\
\hline Constant & -5.624 & -1.5 & -4.790 & -16.6 \\
\hline Innovation output 1996 & 0.295 & 2.9 & & \\
\hline R\&D intensity 1996 or 1998 & 0.067 & 0.5 & 0.615 & 3.9 \\
\hline Size 1994 or 1996 & 0.135 & 0.5 & -0.036 & -0.9 \\
\hline Permanent R\&D facilities & 0.490 & 3.0 & 0.237 & 1.1 \\
\hline Innovation co-operation & 0.174 & 1.1 & 0.002 & 0.0 \\
\hline Technological opportunity "Science" & 0.056 & 0.6 & -0.025 & -0.5 \\
\hline Technological opportunity "Other" & 0.230 & 3.2 & 0.237 & 4.0 \\
\hline Demand-pull important & 2.025 & 9.9 & 0.839 & 6.7 \\
\hline Demand-pull very important & 2.159 & 9.8 & 0.838 & 6.6 \\
\hline Technology-push important & 0.033 & 0.2 & -0.063 & -0.6 \\
\hline Technology-push very important & -0.267 & -1.9 & -0.114 & -1.1 \\
\hline Industry sales growth $1994-96$ or $1996-98$ & 0.003 & 0.2 & -0.026 & -2.7 \\
\hline Process innovation implemented & 0.252 & 1.6 & 0.601 & 7.6 \\
\hline Period dummy & & & 0.512 & 4.4 \\
\hline Heckman's selectivity correction ${ }^{3}$ & 1.096 & 0.3 & $x$ & \\
\hline Pseudo $R^{2}$ & 0.354 & & 0.088 & \\
\hline
\end{tabular}

1. The "dynamic model" covers the period 1996-98; the "pooled" model, the period 1994-96 or 1996-98.

2. Calculated as the (logarithm of the) share of new and improved products in total sales.

3. I did not include a selectivity correction for the pooled model as the preliminary Tobit-selectivity analysis did not indicate a selectivity problem. 


\subsection{The estimates for the innovation equations}

The first, and most notable, point to observe is that the estimates for the lagged dependent variable in the R\&D-intensity equation, as well as the lagged dependent variable in the innovation-output equation are statistically significant and that the estimate is higher (and estimated with more precision) for R\&Dintensities than for innovation output. This result suggests that there is less persistence when innovation is measured from the output side than when it is measured from the input side of the innovation process. Apparently, the often-quoted stylised fact that differences in R\&D intensities across industries are persistent cannot be carried over to the output of knowledge production. Moreover, the coefficient of the lagged R\&D intensity presented in Table 3 may be considered to be too low to make a very strong statement about its persistence on the basis of our data. ${ }^{20}$ In any event, the obtained estimates indicate that, at least for innovative sales, there is a strong tendency towards convergence when using firm-level data. ${ }^{21}$ As mentioned above, the results for innovative sales may be due to a depletion of technological opportunities. One can imagine that this source of non-persistence is far more valid at the firm level than in the aggregate, where the decrease of innovative sales of a particular firm is counterbalanced by an increase of innovative sales of other firms. This leads to the conclusion that there is much turbulence at the firm level, and much turbulence at the product level, hidden behind the observed regularity of aggregate statistics. ${ }^{22}$

From this point of view, it is also understandable that the returns of innovation investment to innovation output (represented by the coefficient of the contemporaneous R\&D intensity in the innovationoutput equation of the model) are small and statistically insignificant in the dynamic model. If the level of product quality achieved captures the history of a firm's R\&D endeavour (and the technological opportunities of this firm are depleted), then the innovation opportunities of the most recent R\&D investments may be small. This is the basic conjecture of the models of Hall and Hayashi (1989) and Klette (1996). ${ }^{23}$ In the dynamic model, the initial level of "innovativeness" in terms of innovation output is controlled for. Thus, the estimate of the contemporaneous R\&D intensity in the innovation-output equation of the dynamic model seems to corroborate Hall and Hayashi (1989) and Klette (1996).

However, this point deserves further reflection for two reasons. First, how should this result be understood, given that I also obtained a much higher estimate for the returns of innovation investment to innovative sales in the static model, where it is about 0.6 and, moreover, rather significant? Second, how to explain the pattern of the estimates for the variable which controls for the presence of permanent R\&D in the two equations? The dynamic model contains two different "forms of control" that are related to the same phenomena. First, let us compare the corresponding estimates for the two versions of the innovationinput equation. The significance of the estimate for the variable that controls for the presence of permanent R\&D facilities is much smaller in the dynamic version of the model than in the "static" equivalent. This should not be surprising, as the dynamic model is aimed at an estimation of R\&D persistence and this persistence has also been captured in the estimate of the lagged $R \& D$ intensity.

20. Note that this stylised fact has often been found when using other types of data, e.g. time-series data for industry aggregates or long R\&D time-series data for very large enterprises.

21. It should be recalled that the models use the broadest definition of innovative sales available, i.e. the share of new and improved products in total sales.

22. To give an example: the simple arithmetic average share of new and improved sales in total sales for 1994-96 (calculated using the 1428 firms of Table 2a) was about 26\%. This is almost equal to the corresponding average for 1996-98 (calculated using the 1618 firms of Table 2b). The same regularity can be observed after weighting the data (see, for example, Statistics Netherlands, 1998, 2000).

23. See the summary of their models in Section 2.1 . 
The next step is to look at the innovation-output equation. The most striking difference between the two versions of the model is the low and insignificant estimate for R\&D intensity in the dynamic model and a much higher (and rather significant) estimate in the static model. By contrast, it can be seen that the impact of performing $\mathrm{R} \& \mathrm{D}$ on a permanent basis is small and insignificant in case of the static version but larger and rather significant in the dynamic model. Thus, these estimates seem to present contradictory results. However, there are reasons to question this interpretation. One can imagine that the level of R\&Dknowledge stocks achieved is dependent on the nature of $R \& D$ investment. A firm that performs $R \& D$ on a permanent basis may have fewer difficulties in building up knowledge stocks than firms that perform R\&D incidentally. Furthermore, one can imagine that the initial level of innovative sales has captured the history of $\mathrm{R} \& \mathrm{D}$ investment to the extent that knowledge-stocks were productive in terms of innovative sales. In the static model, I do not control for the past. Therefore, it is not very surprising that "performing R\&D on a permanent basis" is a better predictor for differences in $R \& D$ intensities than for differences in innovative sales. However, in the dynamic model, I do control for the past at both sides of the innovation process. Nevertheless, I obtained a significant contribution of performing R\&D permanently to innovative sales.

Another, and perhaps more interesting, explanation for the estimated difference in returns to the current R\&D endeavour may be related to the fact that the static model uses many more firms. As a result of the non-rivalry of innovation and (non-intended) "spillover" effects to competitors, there are "new innovators" or "innovation-imitating" firms that were not observed earlier. Such a mixture of "old" and "new" innovators - by definition - can be better taken into account in the static model. Furthermore, the emergence of "new" innovators may explain - in line with the conjecture of Klette (1996) - why the returns to current $R \& D$ endeavour are higher in the static innovation model than in the dynamic version of this model.

All in all, these results make a very strong plea for the importance of performing R\&D on a permanent basis. They also clarify why one cannot rely on R\&D intensities alone. However, at the same time, the results stress that the use of firm-level innovation panel data may not capture all the salient features of the innovation process. Anyway, the results presented in Table 3 underline the benefits of using variables that refer to the organisational aspects of innovation processes and a firm's interaction with its technological environment. As to the latter, it can be seen that our previous results are confirmed for other explanatory variables: I obtained a similar pattern for the impact of the technological opportunity variables "Science" and "Other" in the two equations as in Klomp and van Leeuwen (2001). Again, and in line with the "absorptive-capacity" hypothesis of Cohen and Levinthal (1989), "Science" appears to be more important for predicting differences in R\&D intensities, and "Other" for predicting differences in innovative sales. ${ }^{24}$ Furthermore, the correspondence with the conclusions of our previous research also applies to other results:

- Conditional on selection, there appears to be a negative relation between firm size and R\&D intensity (see also Cohen and Klepper, 1996).

- Large firms do not show better innovation performance in terms of innovation output than small firms.

- The implementation of process innovation contributes positively to innovation output (see also Bartelsman et al., 1998).

24. The decrease in significance for the estimated impact of "Science" to innovation investment when using a dynamic model can be explained by the fact that the contribution of this variable has already been captured in the estimate for the lagged dependent variable. 
- Innovation seems to be predominantly a "demand-driven" process (see the estimates for the variables that refer to the objectives underlying innovation).

\subsection{The contribution of innovation to productivity growth}

This subsection discusses the estimation results of the revenue-per-employee model presented in Table 4. In particular, it pays attention to the contribution of innovation to multifactor-productivity (MFP) growth. According to the theoretical exposition in Section 3, this contribution is given by $\bar{\gamma} \bar{S}=-(\hat{\phi} / \hat{\eta}) \bar{S}$. Therefore, by focusing on innovative sales, the measure for the contribution of innovation to productivity growth follows the quality ladder or product variety model of Grossman and Helpman (1991). Indeed, looking at our firm-level data, it can be observed that many innovations are incremental. It can be verified that a substantial part of the innovating firms have only implemented product improvements. Furthermore, the discussion of the estimates of the two versions of the innovation model presented in Table 3 points to the presence of different forces. A rather low persistence of innovativeness (in terms of having achieved new and improved sales) can be seen when tracking the innovation performance of individual firms over time. On the other hand, a higher return to the current R\&D endeavour has been estimated if "new innovators" or "innovation-imitating" firms are taken into account.

Unfortunately, and by construction, data on the innovation-investment history of these "new" innovators are not available. ${ }^{25}$ I have tried to circumvent this problem by using two alternative measures for innovation output. The full model was recalculated after redefining innovation output as the share of new sales in total sales and then compared the results for the MFP contribution to productivity growth of the two measures of innovation output. Furthermore, the two definitions of innovativeness were applied to the innovation panel as well as to the complete sample (including the firms that were only existent in one wave of CIS). It goes without saying that the different models applied yield different estimates for the innovation-output variable of the productivity-growth model and that the differences between the averages for the innovative output measure chosen should also be taken into account. ${ }^{26}$

By doing so, an estimate for the contribution of innovation to MFP growth is obtained that lies between $0.4 \%$ and $0.9 \%$. It can be seen from Table 4 that these estimates are highest for innovation output defined as the share of new sales in total sales. It is also interesting to see that the latter model version yields the best "fit" to the data. For the models that use new sales, one can observe a higher precision of the corresponding estimates as well as a higher coefficient of determination $\left(\mathrm{R}^{2}\right)$ than in the models that use a less discriminating definition of innovation output, irrespective of the specification for the innovation model used. On the basis of these criteria - and because it is better able to account for "new" innovative firms - the model that uses all available data is adopted as the preferred model.

25. This is a consequence of the fact that only the current innovation costs are collected for firms which stated that they had implemented product or process innovation.

26. If the definition of innovation output is changed to cover new sales only, there are 510 firms in the dynamic model and 1929 firms in the model that uses all available data. 
Table 4. Results for the revenue-per-employee equation ${ }^{1}$

\begin{tabular}{|c|c|c|c|c|}
\hline \multirow[t]{2}{*}{ Use of innovative sales } & \multicolumn{2}{|c|}{ New sales } & \multicolumn{2}{|c|}{ New and improved sales } \\
\hline & Est. & $\mathrm{t}$ & Est. & $\mathrm{t}$ \\
\hline \multicolumn{5}{|l|}{ A) Dynamic model } \\
\hline Number of firms & 510 & & 758 & \\
\hline Constant & 0.518 & 0.5 & -0.046 & -0.0 \\
\hline Physical capital & 0.017 & 1.2 & 0.006 & 0.5 \\
\hline Labour & 0.076 & 1.7 & 0.132 & 3.3 \\
\hline Material inputs & 0.781 & 10.7 & 0.761 & 11.4 \\
\hline Dummy process innovation applied & -1.155 & -1.7 & -0.754 & -1.0 \\
\hline Share of innovative sales & 0.055 & 1.7 & 0.015 & 1.0 \\
\hline Returns to scale & -0.126 & -1.5 & -0.101 & -1.2 \\
\hline Inverse of mark-up & 0.896 & 10.9 & 0.913 & 12.3 \\
\hline Share of innovative sales in total sales & 10.1 & & 27.5 & \\
\hline Contribution of innovation to MFP (\%) & 0.6 & & 0.4 & \\
\hline $\mathrm{R}^{2}$ & 0.630 & & 0.550 & \\
\hline \multicolumn{5}{|l|}{ B) Pooled model } \\
\hline Number of firms & 1929 & & 3046 & \\
\hline Constant & -1.001 & -2.1 & -0.317 & -0.9 \\
\hline Physical capital & 0.020 & 4.1 & 0.014 & 3.5 \\
\hline Labour & 0.117 & 10.5 & 0.142 & 15.0 \\
\hline Material inputs & 0.747 & 28.1 & 0.749 & 36.2 \\
\hline Dummy process innovation applied & -0.196 & -0.4 & -0.245 & -0.7 \\
\hline Share of innovative sales in total sales & 0.115 & 6.8 & 0.030 & 3.8 \\
\hline Returns to scale & -0.116 & -3.8 & -0.095 & -3.9 \\
\hline Inverse of mark-up & 0.966 & 29.0 & 0.946 & 38.2 \\
\hline Share of innovative sales & 8.2 & & 26.4 & \\
\hline Contribution of innovation to MFP (\%) & 0.9 & & 0.8 & \\
\hline$R^{2}$ & 0.714 & & 0.683 & \\
\hline
\end{tabular}

In closing, let us take a look at the other estimates of the revenue model. It can be observed that the precision of the production elasticities of the model increases with the sample size used and that there is a tendency to decreasing returns to scale. However, this conclusion should be interpreted with care as, in general, a rather low (and in some cases insignificant) estimate for the production elasticity of ordinary physical capital can be observed. The latter result is probably due to the approximate measure used for this variable, taking into account that firm-level data of a times-series type rather than cross-sectional differences in levels were used. ${ }^{27}$ Furthermore, it should be noted that the estimates control for the importance of process innovation. In general, the contribution of process innovation to sales-per-employee growth appears to be insignificant. Comparing this result with the estimates of the corresponding variable

27. See, for example, Mairesse (1990) for a detailed account of this issue. 
found in the innovation-output equation, one has to conclude that process innovation contributes relatively more to innovative sales than to non-innovative product lines. A final notable result concerns the estimate for the mark-up factor included in the models. Here, the most sensible results are observed for the model that uses new sales as the measure of innovativeness and that was applied to the panel of innovative firms. This result seems to be in line with the a priori expectation that the underlying market-share model yields the most sensible representation for those firms that are continuously engaged in innovation.

\section{Summary and conclusions}

In this paper, I have presented the first results of an attempt to assess the importance of innovation for inter-firm differences in productivity growth using two similar CIS surveys and, after linking these surveys to the production surveys for the same firms, using the innovation panel to investigate a number of theoretical issues. I have combined recent lines of research in a structural modelling approach that allows the contribution of innovation to multifactor productivity (MFP) growth to be interpreted as a "demandshifting effect". The model rests on the basic assumption that innovation is predominantly "demanddriven", and that its contribution to productivity growth should be measured along the quality ladder or product variety model of Grossman and Helpman (1991). The model also accounts for the joint endogeneity of R\&D investment, innovation output and sales-per-employee growth. Moreover, I have tried to control for the interaction between internal and external knowledge bases, the within-firm time interdependencies of R\&D and innovation output, and the biases in estimation that result from endogenous panel attrition or endogenous selection. Two important points concern: $i$ ) a comparison of the persistence of R\&D investment and innovation output; and ii) a comparison of the contribution to MFP growth based on the innovation panel and based on the set of all firms.

The dynamic model used offers an intuitive form of "controlling" for past innovation history and enables a comparison of the importance of other firm-specific innovation characteristics. The results of this model show that innovation persistence is smaller when measured from the output side of the innovation process than when judged from $R \& D$ intensities. This outcome seems to confirm the conjecture of earlier research, that the returns of current $R \& D$ endeavour become much lower after controlling for the level of innovativeness already achieved. This result also points to a (private) rate of depreciation of "knowledge" which is much higher than that applied when constructing R\&D-capital stocks in the traditional way. Furthermore, and in line with the previous result, I obtained a rather small return to the current R\&D endeavour for the firms included in the innovation panel. Nevertheless, the estimates of the dynamic innovation model underline the importance of being permanently active in R\&D. Controlling for past innovation inputs as well as innovation output, I obtained a significant contribution of performing R\&D on a permanent basis to innovation output.

On the other hand, the returns of the current $R \& D$ endeavour are very different if the dynamic specification is relaxed, and a restricted and static model applied to all available CIS data. For this restricted model, a more pronounced and rather significant estimate for the returns of the most recent R\&D investment endeavour has been found. Conditional on the assumption that many of the additional firms used in the static model are "new innovators" with relatively short innovation histories, this result seems to corroborate the conjecture that the returns to $R \& D$ are highest for firms that have low initial knowledgecapital-stocks.

Finally, to explore the sensitivity of the estimate for the implied contribution of innovation to MFP, I performed an iteration on the specification for the innovation model and the measures of innovation output available. The results of this sensitivity analysis show that, in most cases, there is a significant estimate for the contribution of innovation to MFP, which varies between $0.4 \%$ and $0.9 \%$. 


\section{Appendix 1}

\section{THE BASIC FRAMEWORK FOR R\&D-PRODUCTIVITY MODELS}

This appendix summarises two well-known specifications for the production model that have been used extensively in the R\&D-productivity literature (see e.g. Mairesse and Sassenou, 1991, and Griliches, 1998 for an overview). The model with output $(Q)$ and inputs physical capital $(C)$, labour inputs $(L)$, material inputs $(M)$ and knowledge capital $(K)$ is approximated by a Cobb-Douglas function. Denoting the logarithms of variables with lowercase letters, adding firm subscripts $i$ and omitting time subscripts for the time being, the following difference equations are obtained, where the contribution of $R \& D(R)$ to output growth is represented either by the growth of R\&D-capital (or equivalently knowledge-capital) stocks (Ia) or by the R\&D intensities (Ib):

$$
\begin{aligned}
& \Delta q_{i}=\mu_{1}+\alpha_{1} \Delta c_{i}+\lambda_{1} \Delta m_{i}+\beta_{1} \Delta l_{i}+\gamma \Delta k_{i}+\varepsilon_{1 i} \\
& \Delta q_{i}=\mu_{2}+\alpha_{2} \Delta c_{i}+\lambda_{2} \Delta m_{i}+\beta_{2} \Delta l_{i}+\rho(R / Q)_{i}+\varepsilon_{2 i}
\end{aligned}
$$

The knowledge-capital stocks $(K)$ underlying (Ia) are constructed using the Perpetual-Inventory Method (PIM), usually applied to ordinary capital investment:

$$
K_{t}=(1-\delta) K_{t-1}+R_{t}
$$

and assuming no depreciation of knowledge-capital stocks $(\delta=0) .^{28}$

It is well known that (Ia) yields an estimate $(\gamma)$ of the elasticity of output with respect to innovation capital stocks, whereas (Ib) yields an estimate $(\rho)$ of the (gross) private returns to innovation investment or, more specifically, R\&D. The relation between these two estimates can be expressed as:

$$
\rho \equiv \frac{\partial Q}{\partial K}=\gamma \frac{Q}{K}
$$

Both specifications have the advantage of providing a control for firm-specific and time-invariant differences in production levels, but (Ia) can only be estimated using firm-level time-series data for $K$. However, the construction of R\&D-capital stocks at the firm level can only be accomplished at the cost of a severe loss of information. ${ }^{29}$ In the CIS surveys, a much larger sample of firms is available. Moreover, the data are of a cross-sectional type and this implies that the proposed model should be able to account for the well-known and persistent differences in R\&D intensities across industries. For this reason, I prefer to use specification (Ib).

28. The precise relation between (Ia) and (Ib) is given by $\gamma \Delta k_{i}=\frac{\rho \Delta K}{Q}=\frac{\rho\left(R-\delta K_{-1}\right)}{Q} \approx \rho \frac{R}{Q}$.

29. Similar to other countries, R\&D surveys in the Netherlands have a long tradition. Nevertheless, the linking across time of $R \& D$ data at the firm level is severely hampered by changes in the survey design or by the difficulty in tracking firms over time as a consequence of mutations in the sampling frame, e.g. due to the merging or splitting-up of firms. 
DSTI/DOC(2002)8

Appendix 2

\section{THE EXOGENOUS VARIABLES FOR THE INNOVATION EQUATIONS}

For the identification of the model it is necessary to assign exogenous variables to the jointly endogenous variables. The selection of the exogenous variables has been guided by the following considerations. A distinction is made between: $i$ ) variables that reflect the objectives underlying innovation, the organisational aspects of a firm's innovation process and its technological environment; ii) financial variables; and iii) predetermined firm-specific variables and industry-specific variables that can be considered as exogeneously given to the firm.

The first group of variables refers to the objectives underlying innovation. If the replacement of old products or the improvement of the quality of existing products or the extension of market shares and product ranges were rated as important, the dummy variable $D_{\text {pull }}$ takes on a value of one (and zero otherwise), whereas the rating "very important" is captured by $D_{\text {pull }}$. Similarly, I constructed two "cost-push" dummy variables for the objectives "economising on production costs" (labour cost, cost of material inputs and energy) were considered "important" $\left(D_{\text {push }}\right)$, or "very important" $\left(D_{\text {push } 2}\right)$. The variables representing the organisational aspects of the innovation process are $D_{R \& D}$ (indicating the presence of permanent R\&D facilities), $D_{\text {co-op }}$ (referring to innovating in partnership), and two continuous variables "Science" and "Other" which were derived from a principal components analysis in order to represent the use of technological opportunities.

The relation between the presence of permanent R\&D facilities, "innovation in partnership", and the two technological opportunity variables ("Science" and "Other") can be outlined as follows. One may expect a "costpush" effect on innovation expenditure of the technological opportunity factor "Science" due to the absorptivecapacity argument (see e.g. Cohen and Levinthal, 1989). A co-operation between R\&D firms and research institutes or universities requires relatively high internal research skills in order to assimilate the fruits of the co-operation and to internalise and commercialise the knowledge created during the co-operation. In contrast, R\&D co-operation with, for example, suppliers, customers and competitors is expected to have lower research competence requirements, a smaller impact on the organisation of firms, and thus a lower "cost-push" effect on innovation expenditure than the technological opportunity factor "Science". On the other hand, as mentioned before, informal innovation co-operation may affect innovation output more directly.

The second category of instruments for the modelling of the innovation process consists of financial indicators. For many firms, innovation expenditures consist to a large extent of investment components, e.g. expenditures on inhouse R\&D and/or licences and patents and equipment purchased for the implementation of process innovation. I assume that these investment type expenditures are affected by the availability of financial resources and for this reason I include in the model two financial variables: the ratio of cash-flow to total sales at the start of the observation period $\left(C F_{t-1}\right)$ and a dummy variable that refers to the awarding of innovation subsidies $\left(D_{\text {subs }}\right)$.

The final category mentioned above consists of the variables derived from the production surveys that are assumed to be predetermined or exogenous to the firm. The variables used to serve as an instrument for the endogenous inputs into innovation and innovation output are (the logarithm of) initial employment $\left(l_{t-1}\right)$, the initial market shares of firms $\left(M S_{t-I}\right)$ and the growth rate of industry sales $\left(\Delta \bar{q}_{I t}\right)$, already introduced in the main text of the paper. The first variable enables us to test whether the stylised facts of Cohen and Klepper (1996) concerning the relation between R\&D and size also apply to our data. The two other instrumental variables are used to capture differences in initial states of competitiveness and exogeneously given the potential for sales growth. 
Appendix 3

RESULTS FOR THE GENERALISED TOBIT MODELS

\begin{tabular}{|c|c|c|c|c|c|c|}
\hline \multirow[t]{2}{*}{ Variable } & \multicolumn{3}{|c|}{ R\&D intensity 1998} & \multicolumn{3}{|c|}{ Innovation output 1998} \\
\hline & Est. & SE & $\mathrm{t}$ & Est. & SE & $\mathrm{t}$ \\
\hline Number of firms & 758 & & & 758 & & \\
\hline \multicolumn{7}{|l|}{ A) Probit part } \\
\hline Constant & -0.237 & 0.213 & -1.1 & -0.002 & 0.192 & 0.0 \\
\hline Size 1996 & 0.094 & 0.044 & 2.1 & 0.054 & 0.039 & 1.4 \\
\hline Market share 1996 & -0.006 & 0.006 & -1.0 & 0.002 & 0.004 & 0.5 \\
\hline Own sales growth 1994-96 & 0.005 & 0.003 & 1.9 & 0.003 & 0.002 & 1.4 \\
\hline R\&D intensity 1996 & 0.096 & 0.010 & 10.0 & 0.002 & 0.015 & 0.1 \\
\hline Innovation output 1996 & 0.024 & 0.019 & 1.3 & -0.031 & 0.015 & -2.0 \\
\hline Industry sales growth 1996-98 & 0.002 & 0.007 & 0.3 & -0.003 & 0.007 & -0.5 \\
\hline Cash-flow ratio 1996 & -0.001 & 0.002 & -0.4 & -0.001 & 0.002 & -0.6 \\
\hline \multicolumn{7}{|l|}{ B) Tobit part } \\
\hline Constant & 1.550 & 0.594 & 2.6 & -1.357 & 0.438 & -3.1 \\
\hline R\&D intensity 1996 & 0.487 & 0.011 & 44.1 & 0.030 & 0.044 & 0.7 \\
\hline Innovation output 1996 & 0.011 & 0.058 & 0.2 & 0.180 & 0.034 & 5.3 \\
\hline Size 1996 & -0.169 & 0.105 & -1.6 & -0.069 & 0.082 & -0.8 \\
\hline Market share 1996 & 0.037 & 0.008 & 4.4 & & & \\
\hline Own sales growth 1994-96 & 0.007 & 0.006 & 1.2 & -0.003 & 0.005 & -0.7 \\
\hline Industry sales growth 1996-98 & 0.012 & 0.016 & 0.8 & -0.002 & 0.015 & -0.1 \\
\hline Subsidies awarded & 0.268 & 0.244 & 1.1 & & & \\
\hline Cash-flow ratio 1996 & -0.002 & 0.586 & -0.3 & & & \\
\hline Permanent R\&D facilities & 0.485 & 0.266 & 1.8 & 0.226 & 0.120 & 1.9 \\
\hline Innovation co-operation & 0.213 & 0.193 & 1.1 & 0.086 & 0.116 & 0.7 \\
\hline Technological opportunity "Science" & 0.199 & 0.089 & 2.2 & 0.035 & 0.060 & 0.6 \\
\hline Technological opportunity "Other" & 0.042 & 0.120 & 0.3 & 0.116 & 0.066 & 1.8 \\
\hline Demand-pull important & -0.121 & 0.455 & -0.3 & 0.891 & 0.144 & 6.2 \\
\hline Demand-pull very important & 0.009 & 0.465 & 0.0 & 0.993 & 0.155 & 6.4 \\
\hline Technology-push important & 0.210 & 0.172 & 1.2 & 0.031 & 0.125 & 0.2 \\
\hline Technology-push very important & -0.019 & 0.199 & -0.1 & -0.064 & 0.112 & -0.6 \\
\hline Process innovation implemented & & & & 0.086 & 0.123 & 0.7 \\
\hline$\sigma^{2}$ & 2.205 & 0.090 & 24.5 & 2.382 & 0.073 & 32.6 \\
\hline$\rho_{\text {Tobit }}$ & -0.763 & 0.051 & -15.0 & -0.986 & 0.073 & -13.4 \\
\hline
\end{tabular}




\section{REFERENCES}

Bartelsman, E.J., G. van Leeuwen and H.R. Nieuwenhuijsen (1998), "Adoption of Advanced Manufacturing Technology and Firm Performance in the Netherlands", The Economics of Innovation and New Technology, Vol. 6, pp. 291-312.

Cohen, W.M. and D.A. Levinthal (1989), "Innovation and Learning: The Two Faces of R\&D", The Economic Journal, Vol. 99, pp. 569-596.

Cohen, W.M. and S. Klepper (1996), "A Reprise of Size and R\&D”, The Economic Journal, Vol. 106, pp. 925-951.

Crépon, B., E. Duguet and J. Mairesse (1998), "Research, Innovation and Productivity: An Econometric Analysis at the Firm Level", The Economics of Innovation and New Technology, Vol. 7, pp. 115-158.

Griliches, Z. (1998), R\&D and Productivity, The Econometric Evidence, University of Chicago Press, Chicago.

Griliches, Z. and J. Mairesse (1997), "Production Functions: The Search for Identification", Document de travail CREST 9730.

Grossman, G.M. and E. Helpman (1991), Quality Ladders in the Theory of Growth, Review of Economic Studies, Vol. 58, pp. 43-61.

Hall, B.H. and F. Hayashi (1989), "Research and Development as an Investment", NBER Working Paper No. 2973, National Bureau of Economic Research, Cambridge, Mass.

Klette, T.J. (1996), "R\&D, Scope Economies and Plant Performance", RAND Journal of Economics, Vol. 27, No. 3, pp. 502-522.

Klette, T.J. and Z. Griliches (1996), "The Inconsistency of Common Scale Estimators when Output Prices are Unobserved and Endogenous", Journal of Applied Econometrics, Vol. 11, pp. 343-361.

Klomp, L. and G. van Leeuwen (2001), "Linking Innovation and Firm Performance: A New Approach", International Journal of the Economics of Business, Vol. 8, pp. 343-364.

van Leeuwen, G. and L. Klomp (2001), "On the Contribution of Innovation to Multi-Factor-Productivity Growth", Research Paper 0201, Methods and Informatics Department, Statistics Netherlands.

Leiponen, A. (2001), "Organization of Collaboration: An Empirical Analysis of Knowledge Intensive Business Service Relationships", paper presented at the Workshop on Innovation, Technological Change and Growth in Knowledge-based and Service-intensive Economies, Stockholm. 
Lööf, H. and H. Heshmati (2001), "Knowledge Capital and Performance Heterogeneity: A Firm Level Innovation Study", International Journal of Production Economics, forthcoming.

Mairesse, J. (1990), "Time-series and Cross-sectional Estimates on Panel Data: Why Are They Different and Why Should They Be Equal?", in J. Hartog, G. Ridder and J. Theeuwes (eds.), Panel Data and Labour Market Studies, North-Holland, Amsterdam, pp. 81-95.

Mairesse, J. and M. Sassenou (1991), "R\&D and Productivity: A Survey of Econometric Studies at the Firm Level", STI Review No. 8, OECD, Paris, pp. 9-43.

OECD (1992), "Proposed Guidelines for Collecting and Interpreting Technological Innovation Data: Oslo Manual", OECD, Paris.

OECD (1996), Proposed Guidelines for Collecting and Interpreting Technological Innovation Data: Oslo Manual, $2^{\text {nd }}$ edition, OECD, Paris.

Statistics Netherlands (1998), The Knowledge-based Economy 1998 (in Dutch: Kennis en economie 1998, Voorburg/Heerlen, The Netherlands.

Statistics Netherlands (2000), The Knowledge-based Economy 2000 (in Dutch: Kennis en economie 2000, Voorburg/Heerlen, The Netherlands.

Veugelers, R. (1997), "Internal R\&D Expenditures and External Technology Sourcing, Research Policy, Vol. 26, pp. 303-315.

Veugelers, R. and B. Cassiman (1999), "Make and Buy in Innovation Strategies: Evidence from Belgian Manufacturing Firms", Research Policy, Vol. 28, pp. 63-80. 